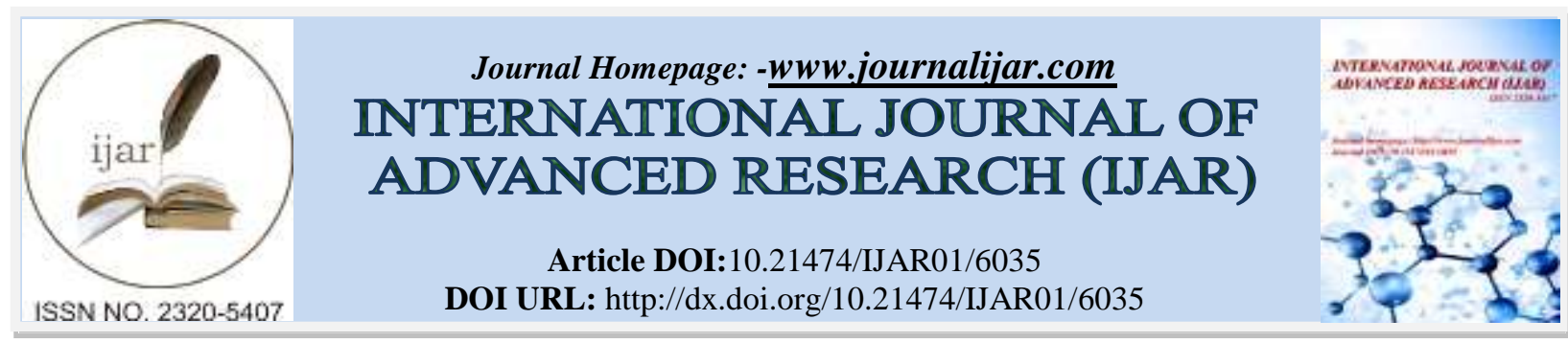

RESEARCH ARTICLE

\title{
A PHARMACOECONOMIC STUDY AND ITS APPRAISAL IN IMPROVING HEALTH CARE OUTCOMES IN PATIENTS SUFFERING FROM TYPE-2 DIABETES AMONG RURAL AREAS IN SOUTH-EAST INDIA.
}

${ }^{*}$ K. Satya Durga ${ }^{1}$, N. Sowmya ${ }^{1}$, S. Charishma ${ }^{1}$, Mrs. P. Sharmila Nirojini ${ }^{2}$ and Dr. Ramarao Nadendla.

1. Pharm.Dintern, Department of Pharmacy Practice, Chalapathi Institute of Pharmaceutical Sciences, Guntur.

2. Associate Professor, Department of Pharmacy Practice, Chalapathi Institute of Pharmaceutical Sciences, Guntur.

3. Principal, Chalapathi Institute of Pharmaceutical Sciences, Guntur.

\section{Manuscript Info}

Manuscript History

Received: 12 October 2017

Final Accepted: 14 November 2017

Published: December 2017

Key words:-

Pharmacoeconomics, cost utility analysis, medication adherence, clinical pharmacist role, economic burden.

\section{Abstract}

Background: Type 2 diabetes mellitus is a chronic metabolic disease which is a major problem in India, resulting not only in significant direct medical costs but also indirect productivity losses due to disability and early mortality.

Objectives: Main objective was to assess the health care cost and to provide health related counselling on Type 2 Diabetes, to assess the medication adherence, to educate patients regarding importance of medication adherence on their disease condition.

Methodology: A prospective observational cohort household study was conducted near the villages of the capital Amaravathi, Andhra Pradesh. The collected sample size was 392 Type -2 diabetic patients. Patient data as well as cost details were collected from the patients for a period of 6 months. The data was analyzed to determine the average treatment cost for diabetes. Medication adherence was assessed using MMAS-8 scale. Patients were educated by clinical pharmacists and follow up was taken. The healthcare outcomes were measured from the medication adherence of the patients.

Results: A sample size of $n=392$ Type- 2 diabetic patients were obtained. Cost utility analysis was performed and the mean cost per month for the drugs used by 392 patients was 4614.68 rupees. Majority of the patients were using Metformin+Glimepiride combinatio n. In monotherapy Metformin was mostly commonly used. The medication adherence was assessed in type- 2 diabetes and conducted a follow up after educating the patient and got a significant $\mathrm{p}$ value of 0.003 .

Conclusion: Economic status of the patient should be considered while prescribing. Due to the cost of medication maximum number of the patients were unable to bear the cost. This is indirectly decreasing the medication adherence which is further increasing the complexity of disease. In addition to that it is increasing the economic burden on the individual due to complications.

Copy Right, IJAR, 2017,. All rights reserved.

Corresponding Author:-K.Satya Durga.

Address:-Pharm.D intern, Department of Pharmacy Practice, Chalapathi Institute of Pharmaceutical 


\section{Introduction:-}

Pharmacoeconomics is defined as "the description and analysis of the cost of drug therapy to health care system and society. It identifies measures and compares the cost and consequences of pharmaceutical products and services. ${ }^{[1]}$

The balance between the cost and benefit can essentially be observed by economic evaluation. It is the systematic and objective framework which helps decision makers to make more informed choices in their everyday working lives.

All economic evaluation has a common structure. They involve explicit measurement of inputs 'cost' and outcomes 'benefits' around medical intervention. ${ }^{[2]}$

Diabetes Mellitus (DM), a disorder of endocrine and metabolism. ${ }^{[3]} \mathrm{DM}$ is a chronic debilitating condition which has affected more than 150 million people worldwide and this number is increasing rapidly. ${ }^{[4]}$

\section{Pharmacoeconomics on type-2 diabetes:-}

The economic burden of DM approximated \$ 132 billion in 2002, which includes direct medical and treatment cost, as well as indirect cost related to disability and mortality. This disorder is the leading cause of blindness in adults aged to 20 to 74 years and the leading contributor of development of End-Stage Renal Disease (ESRD).

Approximately 82,000 lower extremity amputations annually are attributed to DM. Also, cardiovascular events are responsible for two-thirds of deaths in individuals with DM. ${ }^{[5]}$

Pharmacoeconomics offers a complex view on diabetes in the long-term horizon. It evaluates the economic impact of both preventive and therapeutic practices in the long run. The opportunity of influencing both long-term and short-term strategies and the selection of the most effective therapeutic regime is of crucial importance, aiming at maximization of benefits of financial resources expended. ${ }^{[6,7]}$

The disease presents both a clinical and a financial healthcare challenge. On average, individuals with diabetes incur medical expenditures that are 2-3 times higher than would be the case in the absence of diabetes ${ }^{\left[{ }^{[8,9}\right.}$ For diabetes management, glycemic control is fundamental in preventing, delaying, and/or reducing complications ${ }^{[10,11]}$, with both short- and long-term economic benefits. ${ }^{[12]}$ Patients with T2DM are at high risk for adverse cardiovascular $(\mathrm{CV})$ outcomes and have a $2-4$ fold greater risk of stroke compared to the general population. ${ }^{[13,14]}$

Diabetes is a chronic disease that has spread widely, not only in high-income countries (HICs) but also in many lowand middle-income countries (LMICs) over recent decades.

Due to its adverse effect on people's health, diabetes also imposes an economic burden on individuals and households affected as well as on healthcare systems. The economic burden of diabetes was confirmed by Ettaro et al. in a review of cost-of-illness (COI) studies on diabetes mellitus, published in 2004, covering the literature up to the year 2000. The authors concluded that the direct and indirect economic burden of diabetes was "large", and that costs had increased over time. However, the review also noted that significant variation in costing methodologies made it near impossible to directly compare the cost estimates. ${ }^{[15]}$

COI studies generally assess the direct and indirect costs of a particular illness, where the former represent the opportunity cost of resources used for treatment. The indirect costs measure the value of resources lost due the illness, most commonly those caused by losses in productivity due to mortality and morbidity as measured in lost earnings. ${ }^{[16]}$

The healthcare sector in the country has been plagued by low and stagnant government spending and high out of pocket expenditure. The Union Budget 2017 states that overall health budget has increased from INR 39,879 crore ( $1.97 \%$ of total Union Budget) to INR 48,878 crore (2.27\% of total Union Budget). While the increase is welcome, most of it is concentrated towards human resources and medical education. ${ }^{[17]}$ 


\section{Role of Clinical Pharmacist on Counselling Diabetes Patients:-}

Role of pharmacist has changed dramatically in the last three decades. The pharmacists are becoming more patient oriented than product oriented. Counseling was provided by pharmacists to the patients regarding the disease, medications and lifestyle modifications. Therapeutic outcomes were seen to be improved by patient counseling. In diabetes, self management and patient adherence to the prescribed medication and lifestyle modifications is very essential in which pharmacist plays important role. The counseling plan should address the non-pharmacological and pharmacological measures. Education regarding the acute and chronic complications should be given. There is considerable evidence that Pharmacist provided counseling enhances the patient compliance and improves the quality of life outcomes in diabetes and thereby reducing the economic burden on patient.

Diabetes is a chronic condition that has considerable impact on the life of each individual patient. Patient involvement is paramount for the successful care of diabetes. The principal task of the health care team is to give each patient knowledge, self- confidence and support. Patients with diabetes and their families provide $95 \%$ of their care themselves and, as a consequence, educational efforts to improve self- management are central components of any effective treatment plan.

The role of self-management behavior is clear even in studies that address relationships between pharmacologic treatment and outcomes at the physiologic level. The primary goals of DM management are to reduce the risk for microvascular and macrovascular disease complications, to ameliorate symptoms, to reduce mortality, and to improve quality of life. Appropriate care requires goal setting for glycemia, blood pressure, and lipid levels, regular monitoring for diabetic complications, dietary and exercise modifications, appropriate medications, appropriate self monitoring of blood glucose and laboratory assessment of the aforementioned parameters.

Studies have confirmed that the complications of diabetes can be reduced by proper control of blood glucose. The proper control is dependent on the patient's adherence to medications, life style modifications, frequent monitoring of blood glucose, etc and can be influenced by proper education and counseling of the patient. Pharmacists, being one of the indispensable members of the health care team, have an immense responsibility for counseling these patients.

Diabetes, if untreated, can lead to various complications such as neuropathy, nephropathy, retinopathy, hyperlipidema, diabetic foot ulcers, infections, etc. These complications adversely affect the quality of life of the patient and which increases the hospitalization leading to increased direct and indirect medical costs. Quality of life is a multidimensional concept referring to a person's total well being, including his or her psychological, social, and physical health status. It is also well established that pharmacist provided patient counseling improves the quality of life of the diabetic patients.

\section{Role of Clinical Pharmacists on Diabetes Management:-}

Because of the rapid expansion of available therapeutic agents to treat diabetes, the pharmacist's role in caring for diabetic patients has expanded. The pharmacist can educate the patients about the proper use of medication, screening for drug interactions, explain monitoring devices, and make recommendations for ancillary products and services.

The pharmacist, although not the health care professional to diagnose diabetes, is important in helping the patient maintain control of their disease. The pharmacist can monitor the patient's blood glucose levels and keep a track of it. During their contact, the patients can ask the pharmacist any questions they did not ask the physicians and can get further information regarding diabetes. The pharmacist can also counsel the patients regarding insulin administration regularly so that the onset of complications can be postponed by having tight glycemic control. Another important role of pharmacist is always being available to answer the questions of the patients. Overall, it is the pharmacist's role to help a diabetic patient in the best possible way to cope with their disease.

\section{Materials and Methodology:-}

This study was a prospective observational cohort household study. The study was conducted in 6 months period (from December2016 to May 2017). Study site was in villages (Tatireddipalem, Lam, Jonnalagadda, Gorantla) near capital city of Amaravathi, Guntur District ,Andhra Pradesh. Rural areas were choosen in order to create awareness to people and to improve their health literacy.Maximum possible samples were collected during our study period after getting permission from the president of the village to perform our study. The collected sample size was 392 
Type -2 diabetes patients from those villages. Inclusion criteria were people suffering from Type -2 Diabetes above 20years of age along with co- morbidities. Exclusion criteria were subjects with Type I DM Pregnant women, age below 20 years, patients who are not willing to participate in the study, mentally retarded population with Type 2 Diabetes.

Materials used were data collection form meeting the requirements of study protocol, Informed Consent Form, Morisky Medication Adherence Scales-8 (MMAS-8), Type-2 DM Patient Information Leaflet containing information regarding the disease, educating regarding the disease, dietary and lifestyle modifications to be considered in particular condition and importance of adherence to medication. Awareness questionnaire regarding diabetes was also prepared in local language, in order to educate them. Data was analyzed using statistical software Graph Pad Prism 7 for paired t test and GraphPadInstat 3.0 version for Mean, along with that we clinical pharmacists continuously educated throughout the study period so as to benefit the patient reducing morbidity which indirectly reduces the cost.

People suffering from Type-2 Diabetes above 20 years of age were identified and explained them the purpose of our study and taken written consent. Patient demographics and other details like occupation, dietary pattern, social habits, family history and anti diabetic usage were collected.Patients were counseled about the disease, life style modifications and anti diabetic medications. Through regular intervals health awareness camps and home medication reviews were done to state the importance of health and its impact on individual, so as to increase the health literacy which is poor in rural areas so as to give a healthy world.After proper counseling for 5 months w the follow up was taken in the $6^{\text {th }}$ month and compared the improvement of medication adherence of type- 2 diabetic people to assess the decreased cost caused by awareness which helps in reducing further complications and worsening of conditions and the average cost per one month was also assessed.

In this study usage pattern of drugs i.e cost utility analysis was performed. All the types of oral hypoglycemic drugs used in that area were collected. Furtherly, the number of patients using different combinations and who were on monotherapy were categorized and the cost for different brands used by different patients was noted. Then the average cost per month for all the category of drugs being used in that area was calculated. The number of physician visits per year and comorbidities were also assessed.

In this study economic burden was linked with respect to medication adherence, patient counseling and also bringing awareness that generics are cheaper than brands, through which healthcare outcomes were improved. The therapeutic outcome comes from both pharmacological and non pharmacological treatment. Firstly, medication adherence has a major part in improving healthcare outcomes and in rural areas patients adhere on to their therapy continuously only if it is available at affordable cost. Secondly, especially diabetes is a condition which requires dietary and lifestyle changes. The patients should also be warned regarding future risks which can thereby reduce complications. All these are possible through proper counseling to the patient. So here comes the role of a clinical pharmacist as the physicians due to their hectic schedule they are unable to spend much time on an individual. For instance, if a patient is taking his medication appropriately but not adopted to dietary and lifestyle modifications or vice versa there will be no appropriate healthcare outcomes which further increases the complications due to elevated blood glucose levels. As complications increase, the medications to be taken also increase. Sometimes in chronic conditions the patient may even lead to hospitalization which is indirectly raising the economic burden on patient. Hence, the patients should be educated regarding importance of medication adherence, proper counseling and clear awareness regarding generics.

\section{Results:-}

A total of 392 Type-2 Diabetic study participants were identified and involved in the study. Area wise distribution of Type 2 Diabetic patients among different villages was done, it represents the distribution of sample size in different areas (figure 1). Out of all, predominantly were females $(n=215 ; 54.84 \%)$ followed by males $(n=177 ; 45.15 \%)$ in the study areas where the study was conducted. Most commonly effected age group was found to be between $40-60$ years in this study (figure 2$)$. In this study $(n=352 ; 89.79 \%)$ were using branded, $(n=38 ; 9.69 \%)$ were using generics and $(n=2 ; 0.76 \%)$ were not on medication (figure 3). Majority of the patients were using Metformin+Glime piride combination $(n=98 ; 27.8 \%)$. In monotherapy Metformin $(n=116 ; 32.9 \%)$ was mostly used (figure 4). The average drug cost of different oral hypoglycemics for a month was assessed, during the study period some of the patients who were had uncontrollable blood glucose levels through oral hypoglycemic were prescribed with insulin, so

insulin

was

also 
considered (figure 5). The mean cost per month for the drugs used by 392 patients was 4614.68 rupees. Comorbiditie $\mathrm{s}$ were also considered and analyzed (figure 6 ).Number of physician visits per year was analyzed and found that most of them were visiting once a year due to lack of awareness thereby increasing the complications, which is further increasing the economic burden on the patient(figure 7). After proper health education provided for 5 months of span medication adherence before and after follow up were considered which showed a significant $\mathrm{p}$ value 0.03 (table 1).

\section{Discussion:-}

In present study it was found that the number of people suffering from diabetes were more in the age of 30-60 years in the study areas and the economic burden on the patient increased with the age as they are at higher risk of developing complications. This finding was in concordance with study done by Sadanandam Akari1 , et al., [18] (2017) who conducted a study on Health-care cost of diabetes in South India: A cost of illness study whichrevealed that economic burden is high in Diabetic men in the age group of 51-60 years and the cost is more in patients having macrovascular complications.

In this study, the results manifested that majority of the people were prescribed with branded drugs of higher cost despite the availability of cheaper brand of same therapeutic efficacy, which increased the economic burden on the patients and also leading to poor adherence which further increased the economic burden on them due to complications. This study did not mention any brands in particular in order to maintain confidentiality and avoid conflicts among manufacturers. This study was similar to the Suleiman, et al., (2006) [19] study on Pharmacoeconomic Evaluation of Anti-Diabetic Therapy in A Nigerian Tertiary Health Institution study which stated that cost associated with diabetes is enormous. Adequate consideration for cost implication of chosen therapy is indispensable. Economic evaluation of therapy should be encouraged to ensure improved cost effectiveness and efficiency in management.

In current study the results demonstrated that majority of the patients were on combination therapy. Among various combinations that are being used Metformin+Glimepiride $(n=98 ; 27.8 \%)$ was majorly used compared to other drug combinations. In monotherapy Metformin $(n=116 ; 32.9 \%)$ was most commonly used. The people with poor glycaemic control due to no adherence to medication or due to no changes in the dietary habits or due to lack of awareness in administration or due to lack of dietary counseling or due to other possible reasons were given combination of Voglibose+Glimepiride+Metformin and Pioglitazone +Metformin+Glimepiride which costs $5735.55,852$ respectively for $(n=14 ; 3.97 \%),(n=4 ; 1.13 \%)$ of the patients were using them which is an further increase in economic burden on the patients. Insulin was also prescribed for $(n=15 ; 4.26 \%)$ patients, due to poor glycemic control with oral hypoglycemicsalone, which is also expensive.

In this current study the finding showed the patients with co-morbidities and the majority of the people were suffering from macrovascular complications which is increasing their economic burden .Out of our sample we found DM+HTN $(n=122 ; 31.4 \%)$, DM +CVD $(n=98 ; 27 \%)$. This finding was in concordance with the study done by Leelavathi D, et al., ${ }^{[20]}$ (2017) on Assessment of cost of illness for diabetic patients in South Indian tertiary care hospital which stated that cost of illness is comparatively high in patients with complications than Diabetes alone Similarly literature stated that macrovascular comorbid conditions are a major driver of health care costs in patients with diabetes, including both increased direct health care cost and lost indirect productivity cost.

In this current study the financial cost was assessed and it was found that people of same area had different financial costs because some have regular visits to physician where as some have bimonthly visits. We even found majority of them used to visit once a year $(n=127 ; 32.37 \%)$ due to lack of awareness or poor economic status, which leads to complications and this inturn increases the cost of illness and direct medication cost. Whereas, in Ernest AttuquayeQuaye, et al., ${ }^{[21]}$ (2015) study on Analysis of the Financial Cost of Diabetes Mellitus in Four Cocoa Clinics of Ghana which revealed that a mean age of detection suggested delay in diagnosis of diabetes mellitus and accompanying complications, which had cost implications hence, their study stated that policy that enhances early detection of diabetes in clinical practice would therefore improve management and reduce costs. The financial cost of managing diabetes can be used to forecast the economic burden of the disease in the area.

In this present study medication adherence among the diabetic patients was assessed and the patients were educated regarding importance adherence. Follow up was conducted which showed the significant $\mathrm{p}$ value of 0.003 , which revealed that there is an association between patient counselling and medication adherence. 


\section{Conclusion:-}

The number of people suffering from diabetes were more in the age of 30-60 years and the economic burden on the patient increased with the age as they are at higher risk of developing complications. Majorly females were more prone to diabetes in our study site. Therefore, importantly economic status of the patient need to be considered while prescribing especially for the people belonging to rural areas where the economic status of them is low , because due to cost of medication maximum number of patients may not receive treatment which indirectly decreases the medication adherence which increases the complexity of disease which further increase the economic burden on the individual due to complications.

The policymakers should make policies on dietary guidelines on diabetes, so that there will be improved therapeutic outcomes for the prescribed therapy which further improves the quality of life patients as diet also plays an important role in maintaining proper health condition. Besides that a clinical pharmacist also plays an important role in educating the patient regarding disease condition, to provide information regarding drug administration, its uses, importance of medication adherence, health insurance policies, to warn about the complications and also to mention the dietary modifications especially in diabetes and hypothyroid condition which has equal importance as drug in attaining the positive therapeutic outcomes as in this modern era physicians are presented with downting number of diseases and possible treatments, so they don't have much time to spend with individual patient to educate them so here comes the role of clinical pharmacist to educate the patient. All five players: the patient, the prescription, the dietary advice, the physician and the pharmacist plays an important role in reducing the economic burden of the patient and reducing significant direct medical costs and also reduces indirect productivity losses due to disability and early mortality.

\section{Limitations Of Our Study:-}

$\checkmark$ Follow up was bit difficult due to occupational status of the study population

$\checkmark$ Type-1 DM can also be considered

$\checkmark$ Low health literacy

$\checkmark$ Most of the people in our study were illiterate so it took time for them to understand the importance of patient education

\section{Future Implications:-}

$\checkmark$ Planning to extend to other remaining villages around the capital city

$\checkmark$ Planning to work together with the government authorities and other reputed organizations

\section{Illustrations:-}

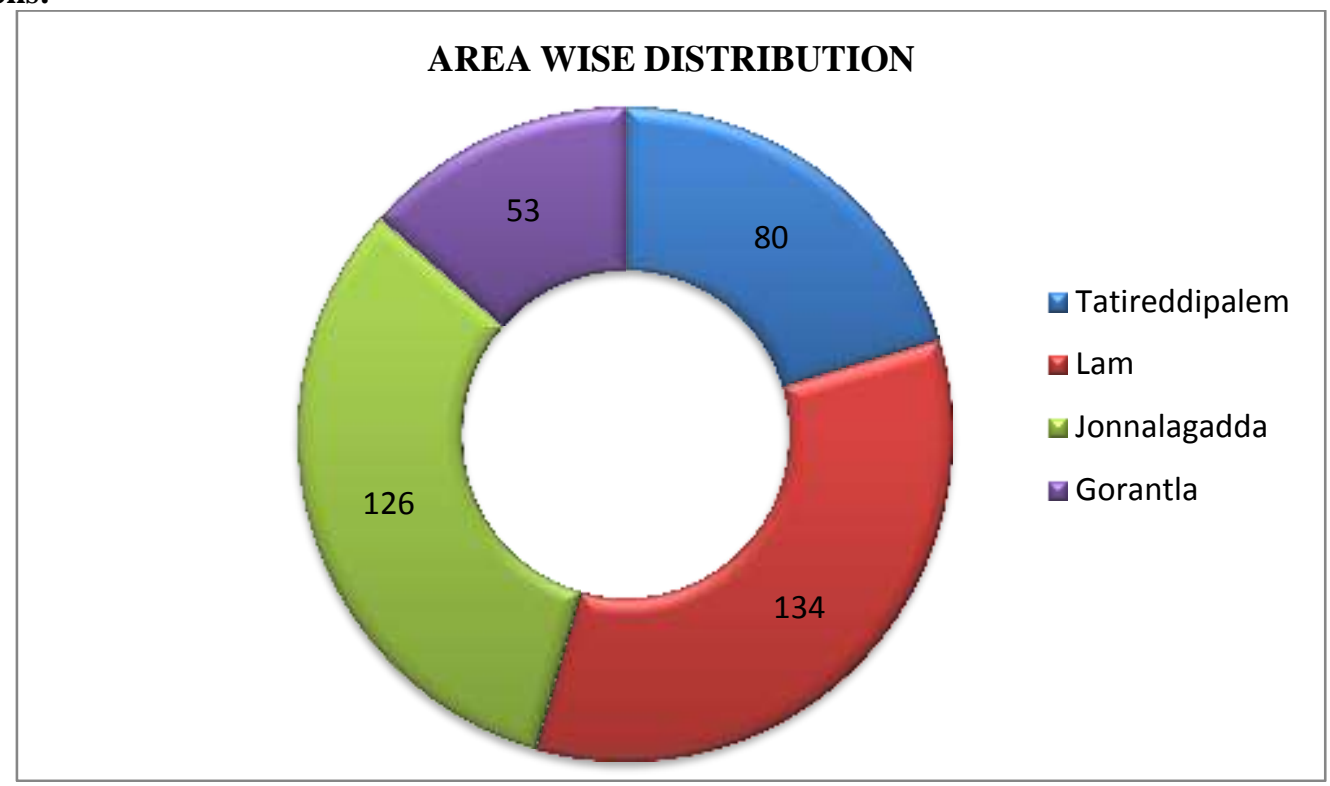

Figure 1:-Number of Type-2 Diabetic patients from different areas 


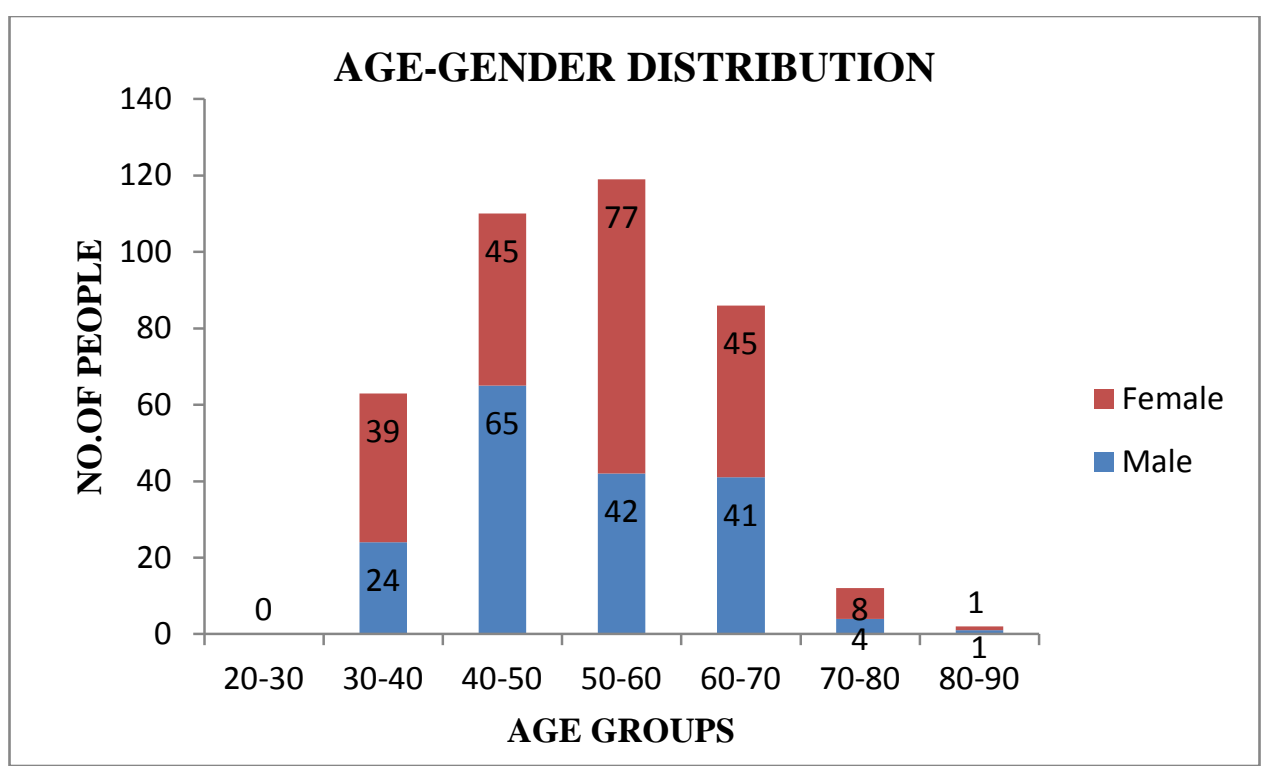

Figure 2:-Age -Gender distribution in Type-2 Diabetic patients.

\section{TYPE OF DRUG USAGE IN T-II DM}

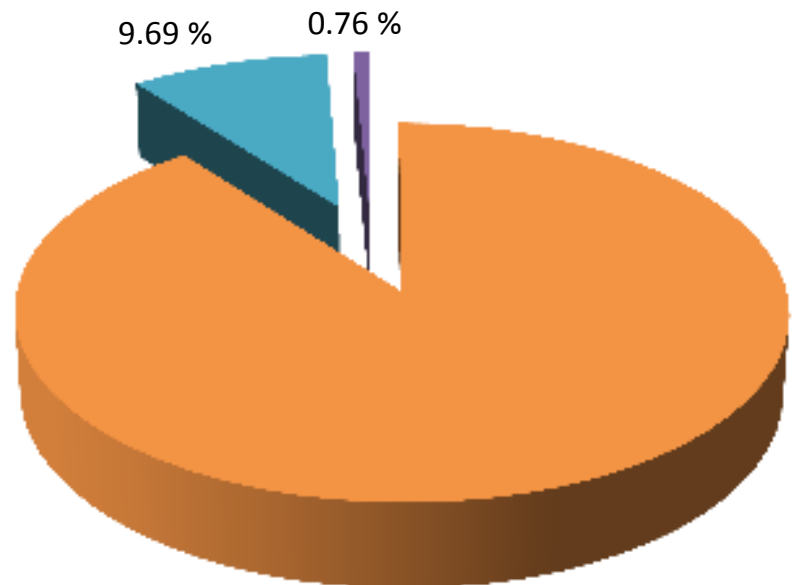

Branded

Generics

not on medication

$89.79 \%$

Figure 3:-Percentage of people on types of drug usage. 


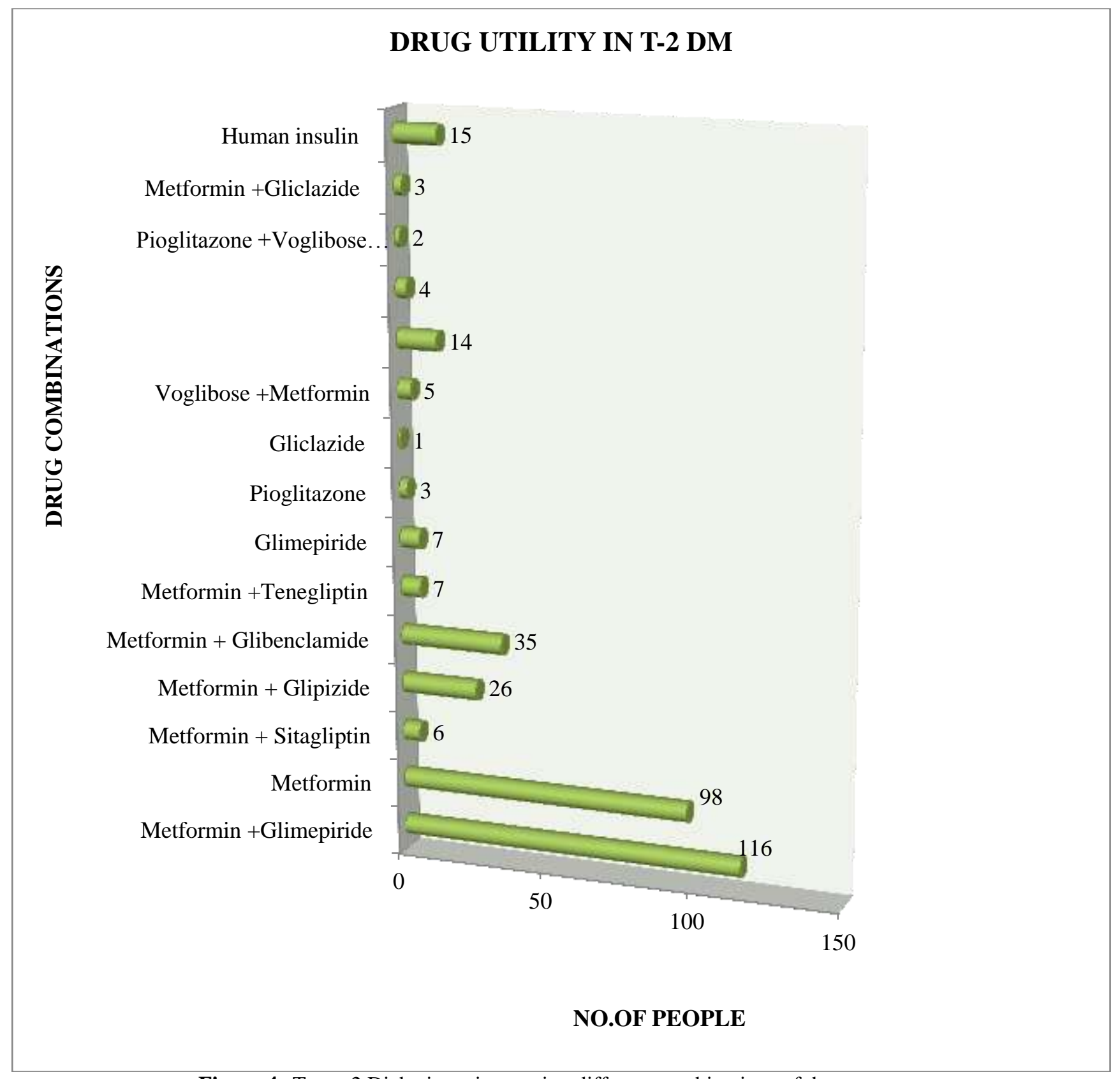

Figure 4:-Type -2 Diabetic patients using different combinations of drugs 


\section{AVERAGE DRUG COST PER MONTH IN T-II DM PATIENTS}

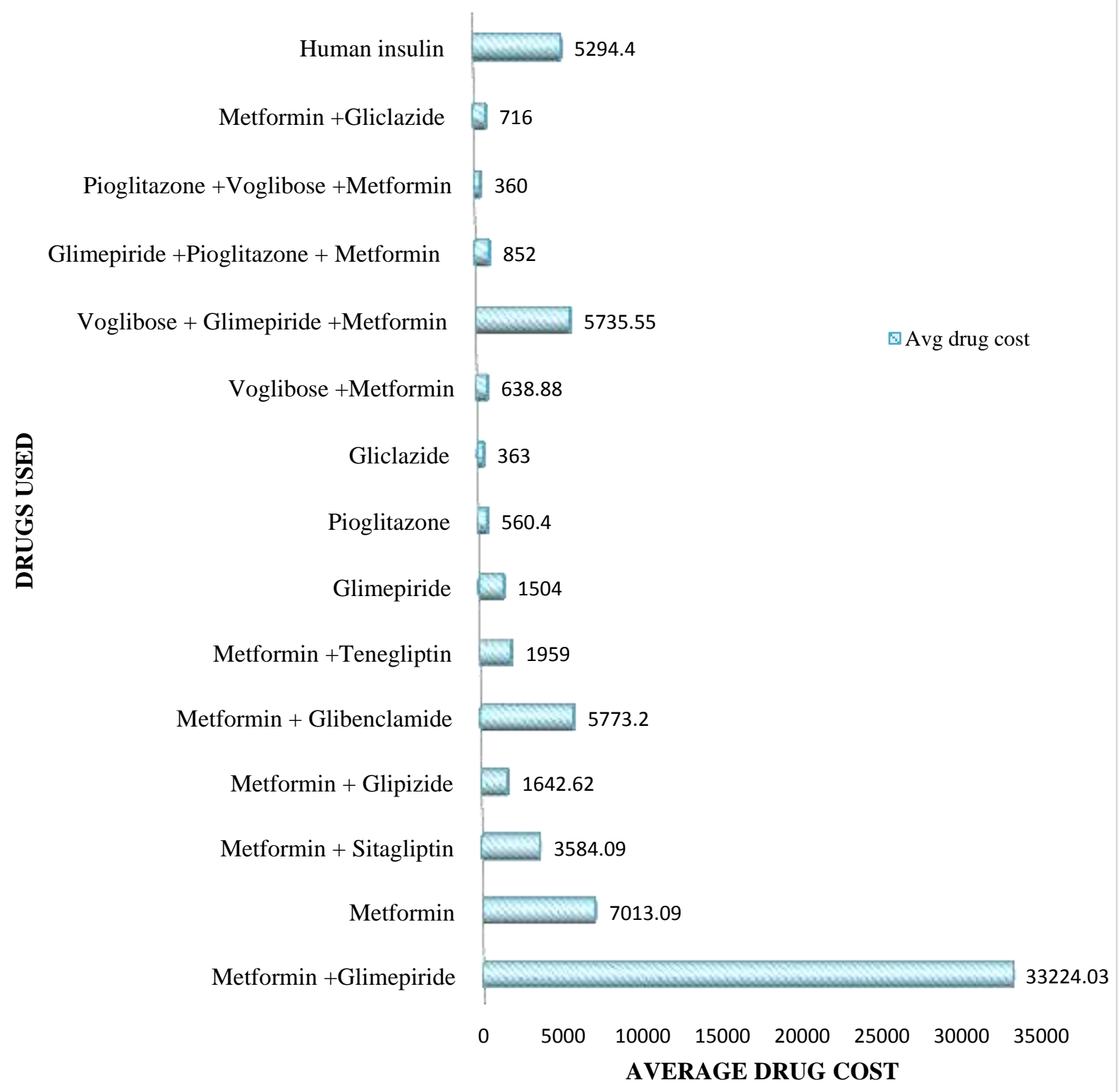

Figure 5:-Average drug cost of Type-2 Diabetic patients using different drug combinations 


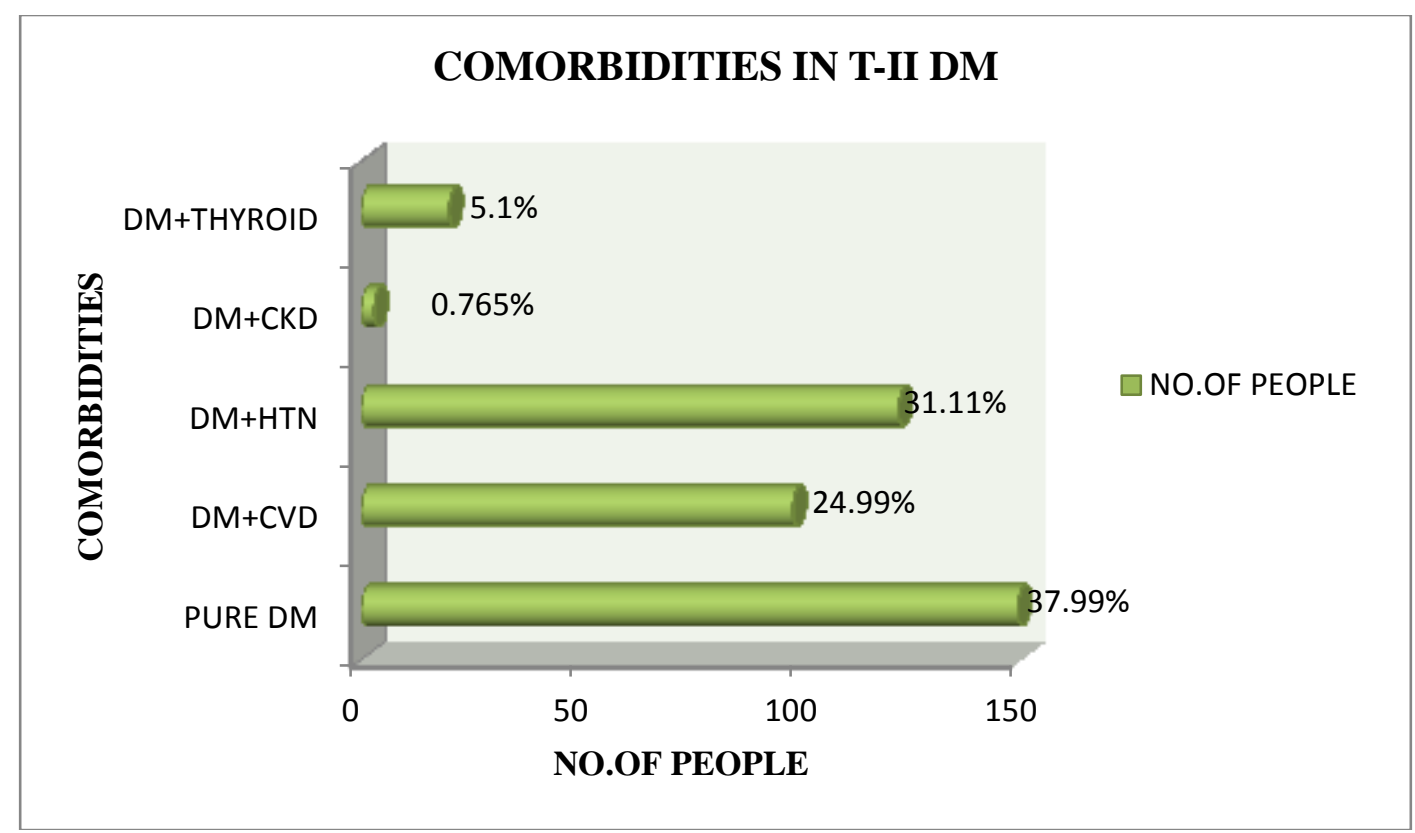

Figure 6:-Co-morbid conditions among Type-2 Diabetic patients.

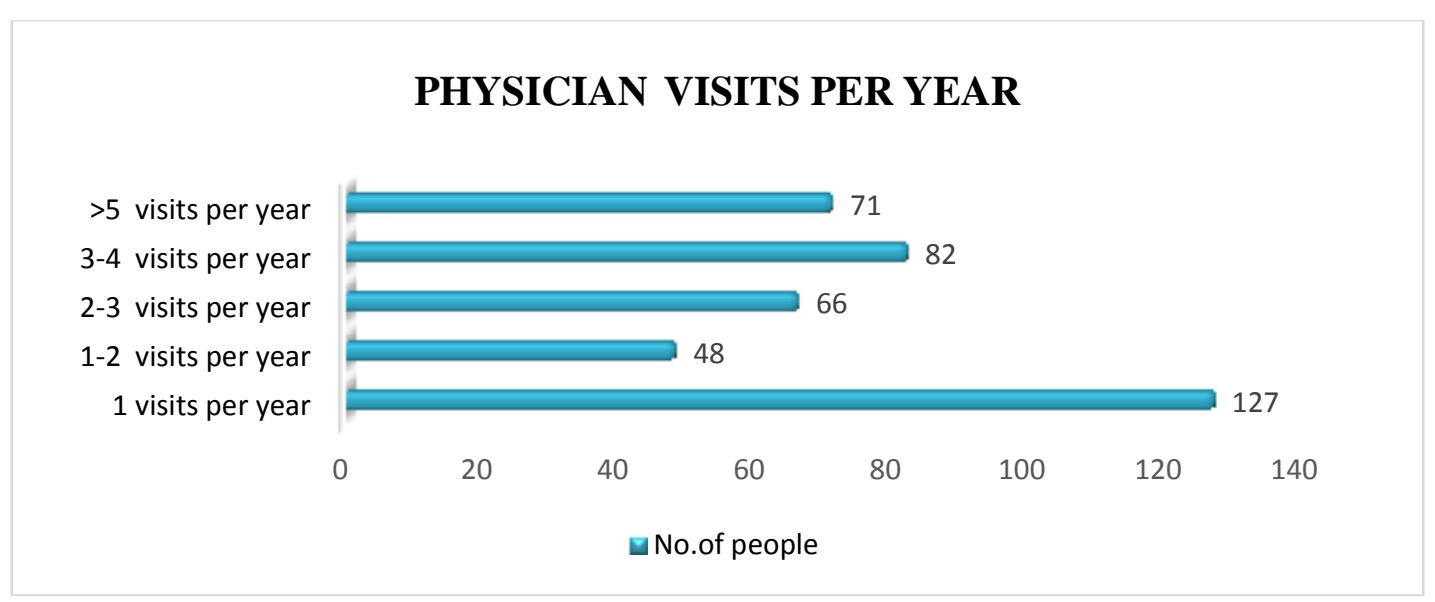

Figure 7:-Physician visits per year among Type-2 Diabetic patients

Table 1:-Morisky Medication Adherence Scales (MMAS-8)

\begin{tabular}{|l|l|l|l|l|l|}
\hline & & \multicolumn{2}{|l|}{ Before follow up } & \multicolumn{2}{|l|}{ After follow up } \\
\hline Q.No & Questions & $\begin{array}{l}\text { YES } \\
(+1)\end{array}$ & $\begin{array}{l}\text { NO } \\
(0)\end{array}$ & $\begin{array}{l}\text { YES } \\
(+1)\end{array}$ & $\begin{array}{l}\text { NO } \\
(0)\end{array}$ \\
\hline 1 & Do you sometimes forget to take your pills? & 211 & 181 & 189 & 203 \\
\hline 2 & $\begin{array}{l}\text { People sometimes miss taking their medications for } \\
\text { reasons other than forgetting. Thinking over the past } \\
\text { two weeks, were there any days when you did not } \\
\text { take your medicine? }\end{array}$ & 223 & 169 & 213 & 179 \\
\hline 3 & $\begin{array}{l}\text { Have you ever cut back or stopped taking your } \\
\text { medicine without telling your doctor because you felt } \\
\text { worse when you took it? }\end{array}$ & 256 & 136 & 221 & 171 \\
\hline 4 & $\begin{array}{l}\text { When you travel or leave home, do you sometimes } \\
\text { forget to bring along your medicine? }\end{array}$ & 117 & 275 & 101 & 291 \\
\hline 5 & Did you take all your medicine yesterday? & 312 & 80 & 336 & 56 \\
\hline
\end{tabular}




\begin{tabular}{|l|l|l|l|l|l|}
\hline 6 & $\begin{array}{l}\text { When you feel like your symptoms are under control, } \\
\text { do you sometimes stop taking your medicine? }\end{array}$ & 246 & 146 & 219 & 173 \\
\hline 7 & $\begin{array}{l}\text { Taking medicine every day is a real inconvenience } \\
\text { for some people. Do you ever feel hassled about } \\
\text { sticking to your treatment plan? }\end{array}$ & $\begin{array}{l}\text { How often do you have difficulty remembering to } \\
\text { take all your medicine? } \\
\text { A. Never/rarely } \\
\text { B. Once in a while } \\
\text { C. Sometimes_ } \\
\text { D. Usually } \\
\text { E. All the time_ }\end{array}$ & 271 & 121 & 249 \\
\hline 8
\end{tabular}

\section{Acknowledgement:-}

We sincerely acknowledge the patients for their kind cooperation \& patience for successful completion of our research.

\section{Conflicts Of Interests:-}

None

\section{References:-}

1. Rascati KL. Essentials of Pharmacoeconomics. Philadelphia (USA): Lippincott Williams \& Wilkins; 2009.

2. Tom Walley, Alan Haycox, Angela Boland, Pharmacoeconomics, Churchill Livingstone Title ISBN: 978-0443-07240-6

3. Talwalkar PG.7. Practical Diabetes Mellitus, 5th ed. Mumbai, India. 2017. Available from: https://www.practo.com/mumbai/doctor/dr-pradeep-talwalkar accessed on March 2017

4. Schmitz P, Martin KJ, Miller DD. Internal Medicine Just the Facts. New York: McGraw Hill Companies; 2008.

5. Dipiro JT, Talbert RL, Yee GC, Matzke GR, Wells BG, Posey LM. Pharmacotherapy A Pathophysiologic Approach, 7th Ed. New York: McGraw Hill Companies; 2008.

6. Shah JV, Patni KN, Deshpande SS. Achieving Glycemic Control of Diabetic Patients through Clinical Pharmacist Provided Counseling. Journal of Pharmaceutical Science and Bioscientific Research 2015; 5(4): 322-327.

7. Ettaro L, The economic burden of diabetes, Pharmaeconomics, 2004, 22, p. 149-164

8. Hoerger T, Segel J, Gregg E, Saaddine J. Is Glycemic Control Improving in U.S. Adults?. Diabetes Care. 2007;31(1):81-86.

9. Wild S, Roglic G, Green A, Sicree R, King H. Global Prevalence of Diabetes: Estimates for the Year 2000 and Projections for 2030: Response to Rathman and Giani. Diabetes Care. 2004;27(10):2569-2570.

10. Economic Costs of Diabetes in the U.S. in 2002. Diabetes Care. 2003;26(3):917-932.

11. Economic Costs of Diabetes in the U.S. in 2007. Diabetes Care. 2008;31(3):596-615.

12. King P, Peacock I, Donnelly R. The UK Prospective Diabetes Study (UKPDS): clinical and therapeutic implications for type 2 diabetes. British Journal of Clinical Pharmacology. 2001;48(5):643-648.

13. Nathan DM, Genuth S, Lachin J, Cleary P, Crofford O, Davis M, et al., The Effect of Intensive Treatment of Diabetes on the Development and Progression of Long-Term Complications in Insulin-Dependent Diabetes Mellitus. New England Journal of Medicine, 1993;329(14):977-986.

14. Clarke P, Gray A, Briggs A, Stevens R, Matthews D, Holman R. Cost-utility analyses of intensive blood glucose and tight blood pressure control in type 2 diabetes (UKPDS 72). Diabetologia. 2005;48(5):868-877.

15. Ettaro L, Songer T, Zhang P, Engelgau M. Cost-of-Illness Studies in Diabetes Mellitus. PharmacoEconomics. 2004;22(3):149-164.

16. Segel JE. Cost-of-Illness Studies-A Primer. RTI-UNC Center of Excellence in Health Promotion Economics; 2006.

17. Budget 2017: What it means for the healthcare sector | Forbes India Blog. Forbes India. 2017. Available from: http://www.forbesindia.com/blog/economy-policy/budget-2017-what-it-means-for-the-healthcare-sector/

18. Mateti U, Kunduru B, Akari S. Health-care cost of diabetes in South India: A cost of illness study. Journal of Research in Pharmacy Practice. 2013;2(3):114. 
19. Suleiman, et al., A.Suleiman, O. F. Fadeke and O. Okubanjo, Pharmacoeconomic Evaluation of Anti-Diabetic Therapy in A Nigerian Tertiary Health Institution, ; 2006; vol.(5): 132 - 137

20. Acharya L, Rau N, Udupa N, Rajan M, Vijayanarayana K. Assessment of cost of illness for diabetic patients in South Indian tertiary care hospital. Journal of Pharmacy AndBioallied Sciences. 2016;8(4):314.

21. Fu A, Qiu Y, Radican L, Wells B. Health Care and Productivity Costs Associated With Diabetic Patients With Macrovascular Comorbid Conditions. Diabetes Care. 2009;32(12):2187-2192. 